\title{
Internet sources of government information
}

\author{
By Blake Gumprecht
}

\section{From the weather to NAFTA, it's on the Net}

$\mathbf{T}$ he Internet, the global computer network that is becoming an increasingly valuable source of information on a wide variety of subjects, has proven an especially rich resource for government information, in part because works produced by the U.S. government are not eligible for copyright protection.

While government agencies have been criticized for not making more information available online, enterprising librarians, professors, business people, and watchdog groups have themselves made a wealth of information available via the network. Internet users can now access hundreds of sources of current government information-census data, Supreme Court decisions, weather forecasts, the Federal Register, daily White House press briefings, Bureau of Commerce reports, and much more.

More and more government agencies too are beginning to establish systems that can be accessed remotely. You can now e-mail the President, and passage of the Government Printing Office (GPO) Electronic Information Access Improvement Act of 1993 assures GPO's role in distributing information electronically will increase. A variety of other proposals suggest that in the future, an ever-increasing volume of government information will be available online, sometimes exclusively.

In many cases, there are significant advantages to the sources accessible online over what can be found in the library or via other means. Internet resources are often more up-to-date than their paper counterparts. Frequently they can be searched by keyword. Sometimes they provide information simply not available in more traditional formats. A word of warning is necessary, though. Internet resources are constantly changing. What is available one minute may not be available the next. Source and file names are often changed without notice.

This article presents a sample of Internet sources of government information and was culled from a longer list created for users at Temple University. The sources listed are intended to provide the simplest route to the information described. The preferred source is often a gopher source because of the ease of using the gopher software. Often, however, there are several sources for the same information. When the source listed is a gopher source, the instructions assume users can escape the local gopher menu structure to connect directly to a remote gopher. This can normally be done by issuing the gopher command in combination with a remote system address from your system's ready prompt.

The longer version of the guide can be retrieved electronically from the University of Michigan's Clearinghouse of Subject-Oriented Internet Resource Guides (source: gopher gopher.lib.umich.edu / general reference resources / clearinghouse... / guides on the social sciences / government ...) or the NorthWestNet ftp archive (source: ftp ftp.nwnet.net / user:anonymous / password: ident / cd user-docs / cd government / get gumprecht-guide.txt).

In the list that follows, the "source" is the "address" of the remote computer where the information can be found, along with the "path" a user must take to locate the directory or file that contains the information. Slashes in the 
source separate commands, steps, or levels in a menu or file hierarchy.

\section{General resources}

- Catalog of Federal Domestic Assistance: Provides information about more than 1,000 U.S. government assistance programs. Searchable by keyword. Source: gopher marvel.loc.gov / federal government information / federal information resources / information by agency / general information resources.

- Copyright Information: Library of Congress system allows users to search information about works registered in the U.S. Copyright Office since 1978. Source: telnet locis.loc.gov.

- Federal Information Exchange: Provides information about federal education and research programs, scholarships, fellowships, grants, programs for minorities, procurement opportunities, and more. Source: gopher fedix.fie.com.

- Federal Jobs: Lists thousands of U.S. government job openings taken from a variety of federal computer bulletin boards. Source. gopher dartcms1.dartmouth.edu / job openings in the federal government.

- FedWorld: National Technical Information Service system provides access to more than 100 U.S. government computer bulletin boards. Also includes full text of select government publications, statistical files, federal job lists, and more. Source: telnet fedworld.gov.

- Geographic Names Database: Provides latitude and longitude, county and state location, elevation, and more for thousands of places in the U.S. Searchable by place name or zip code. Source: gopher gopher.micro. umn.edu / libraries / reference works / u.s. geographic names database.

- Library of Congress Information System: Provides access to the library's online catalog, copyright files, databases containing information on federal legislation and foreign law, and more. Source: telnet locis.loc.gov.

- Library of Congress Marvel: One-stop source for a multitude of government material-Congressional information, census data, White House documents, State Department reports, and more. Source: gopher marvel.loc.gov.

- National Weather Service Forecasts: Provides forecasts, current conditions, information on earthquakes, and more for the 50 states and Canada. Source: gopher ashpool.micro.umn. edu/ weather.
- State Department Travel Advisories: An archive of State Department travel information and advisories arranged by country. Files include country descriptions, current conditions, entry requirements, embassy locations, information about medical facilities, drug penalties and more. Source: gopher gopher.stolaf.edu / internet resources.

- World Factbook (1990-1992): Full text of the CIA-produced annual which provides information about the geography, people, government, and economy of countries around the world. Source: gopher wiretap.spies.com / electronic books / cia world factbook.

\section{Political science, law, and government}

- Budget of the United States Government Full text of the proposed budget for the 1994 fiscal year; can be searched by keyword. Source: gopher sunsite.unc.edu / worlds of sunsite / us and world politics / proposed budget.

- Campaign '92 and Election Results: Full text of key position papers, speeches, press releases, and more from major candidates in the 1992 presidential election. Source: gopher tamuts.tamu.edu / browse information by subject / political science.

- Code of Federal Regulations: Commercial system allows users to browse the code or search it by keyword. Access to the complete CFR is not yet available. System places limits on the amount of information nonsubscribers can retrieve. Source: gopher gopher.netsys.com $/$ counterpoint publishing.

- Congressional Directories: Library of Congress system provides access to a variety of directories. Source: gopher marvel.loc.gov / u.s. congress.

- Congressional Information: Provides access to directories, committee rosters, NAFTA documents, the Americans with Disabilities Act, and more. Source: gopher gopher.lib.umich.edu / social sciences resources/government and politics / u.s. government resources: legislative branch.

- Congressional Legislation: Library of Congress system allows users to search files that describe and track legislation introduced in Congress from 1973 to present. Source: telnet locis.loc.gov / federal legislation.

- Executive Branch Resources: Provides access to executive branch directories, White House information, NAFTA documents, and more. Source: gopher gopher.lib.umich.edu / social sciences resources / government and 
politics / u.s. government resources: executive branch.

- Federal Register: Commercially produced system allows users to browse or search the daily Federal Register. System places limits on the amount of information nonsubscribers can retrieve. Source: gopher gopher.netsys.com / counterpoint publishing.

- National Performance Review: Full text of the report of Vice-President Al Gore's task force on reinventing government. Source: gopher sunsite.unc.edu / worlds of sunsite / us and world politics.

- Presidential Documents from the Federal Register: Full text of presidential proclamations, executive orders, and other documents. Source: gopher gopher.netsys.com / counterpoint publishing / federal register / selected agencies.

- Supreme Court Decisions: Full text of decisions issued since 1989. Source: gopher info.umd.edu / educational resources / united states.

- Treaties and International Covenants: Full text of major treaties. Source: gopher fatty.law.cornell.edu / foreign and international law / multilateral treaties.

- United Nations: Full text of U.N. press releases, U.N. Conference on Environment and Development reports, United Nations Development Programme documents, telephone directories, and more. Source: gopher nywork1. undp.org.

- White House Information: Full text of policy statements, press briefings, speeches, the president's daily schedule, and more. Source: gopher tamuts.tamu.edu / browse information by subject / political science / information from the white house. Source: gopher sunsite. unc.edu / worlds of sunsite / us and world politics / sunsite political science archives / whitehouse-papers.

- World Constitutions: Full text of constitutions of countries worldwide. Source: gopher wiretap.spies.com / government docs. Other constitutions can be accessed by conducting a gopher Veronica search, using "constitution" as the keyword.

\section{Social sciences and humanities}

- AskERIC: Archive of education information compiled by an Internet question-answering service for educators at Syracuse University. Source: gopher ericir.syr.edu.

- Bureau of Justice Statistics Documents: Full text of select Bureau publications. Source: gopher uacsc2.albany.edu / united nations justice network.

- Census of Population and Housing: 1990 Census data available for U.S. cities, counties, metropolitan areas, states, and the nation, with comparisons from 1980. Source: gopher bigcat.missouri.edu / reference center.

- Criminal Justice Country Profiles: Full text of a series of U.N. reports on crime and criminal justice in 123 countries. Source: gopher uacsc2.albany.edu / united nations justice network / u.n. criminal justice country profiles.

- Economic Bulletin Board: Department of Commerce system provides access to thousands of files containing information about current economic conditions, economic indicators, employment, trade, and more in 20 general subject areas. Source: gopher gopher.lib.umich.edu / social sciences research / economics. Source: telnet ebb.stat-usa.gov.

- Educational Resources Information Center (ERIC): Provides keyword access to abstracts of articles and publications about education. Source: gopher spc.syr.edu / local resources.

- Gross State Product Tables: Provides access to U.S. Bureau of Economic Analysis tables estimating the value of goods and services for 61 industries in 50 states. Source: gopher gopher.lib.umich.edu/social sciences research $/$ economics.

- North American Free Trade Agreement: Full text of NAFTA and related documents. Source: gopher cyfer.esusda.gov / americans communicating electronically.

- Radio Free Europe/Radio Liberty Research Institute Daily Report: Full text of a daily digest of developments in Russia, Transcaucasia and Central Asia, Central and Eastern Europe. Source: gopher gopher.lib.umich.edu / news services.

- Statistics Canada Daily Reports: Full text of daily statistical releases, lists of publications, and more from Canada's primary compiler of statistics. Source: telnet info.carleton.ca / terminal type:decvt100.

\section{Physical sciences, health, and medicine}

- AIDS Information: Provides AIDS statistics, daily summaries of newspaper articles about AIDS, full text of AIDS Treatment News, reports from the National Commission on AIDS, and more. Source: gopher gopher.niaid.nih.gov.

- CancerNet: Full text of National Cancer Institute fact sheets, publications, patient diag- 
nosis statements, and more. Source: gopher helix.nih.gov / health and clinical information.

- Chemical Substance Fact Sheets: Full text of EPA fact sheets about hundreds of chemicals. Can be browsed or searched by keyword. Source: gopher ecosys.drdr.virginia.edu / education/ environmental fact sheets.

- Cooperative Extension System: Department of Agriculture system provides access to extension service reports, directories, nutritional data, and more. Source: gopher esusda.gov.

- Earthquake Information: Provides data about recent earthquakes worldwide. Source: gopher gopher.stolaf.edu / internet resources / weather and geography

- Food and Drug Administration Bulletin Board System: Full text of FDA news releases, enforcement reports, import alerts, drug and product approval lists, Federal Register summaries, articles from FDA Consumer, and more. Source: telnet fdabbs.fda.gov / login:bbs.

- Health Security Act: Full text of the Clinton administration's health plan and related documents. Act can be browsed or searched by keyword. Source: gopher sunsite.unc.edu / worlds of sunsite / us and world politics / national health security plan.
- Morbidity and Mortality Weekly Report: Full text of the Centers for Disease Control and Prevention weekly publication. Source: gopher gopher.niaid.nih.gov / aids related information.

- National Institutes of Health: Provides access to NiH phone books, calendars, library catalogs, molecular biology databases, NIH Guide for Grants and Contracts, and more. Source: gopher gopher.nih.gov.

- National Science Foundation: Provides access to grant information, NSF directories, press releases, full text of foundation publications, and more. Source: gopher stis.nsf.gov.

- PENpages: Pennsylvania State University system provides the full text of thousands of documents about agriculture, food and nutrition, family issues, and more. Source: telnet psupen.psu.edu / username:penpages.

- Spacelink: NASA system provides access to shuttle status reports, mission summaries, NASA news releases, and other files with current and historical information about NASA. Source: telnet spacelink.msfc.nasa.gov/ username:newuser / password:newuser.

- World Health Organization: Provides access to world health statistics, full text of selected WHO publications, and more. Source: gopher gopher.who.ch.

Dear Swami Romma:

In this life, I am a research specialist working in an academic library. My shelf space is disappearing before my eyes, my budget is shrinking, and requests for services are way up. Talk about bad karma! What am I to do? Your words of wisdom will set me upon the right path. -Uncentered in Ukiah

Dear Uncentered:

Not to worry! The Swami knows all and tells all. Call sociological abstracts, inc. and they will ease your worries with two CD-ROMs created especially for professionals like you. Both sociofile and LLBA Disc contain timely abstracts of theoretical and applied research in sociology and linguistics, and are priced for down-to-earth budgets like yours. Their subject specialists track more than 1,900
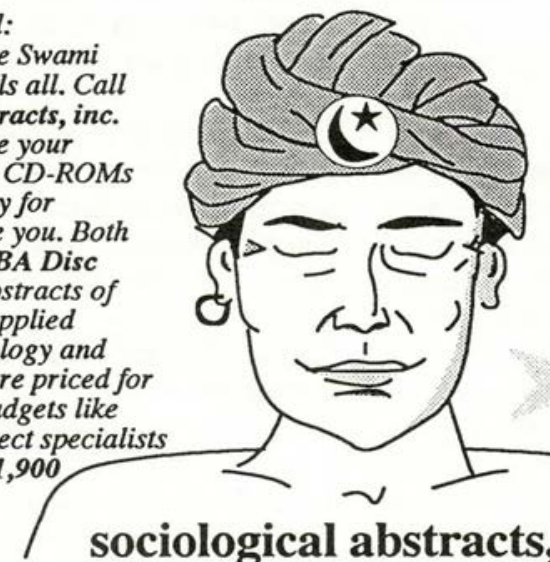

journals, as well as selected books, book reviews, and conference proceedings-all from an international perspective. Both sociofile and LLBA Disc offer comprehensive backfiles (this lifetime only) and retrieval software that makes searching easy for both novice and savvy souls. And, unlike life, they include a user's manual to ensure a stress-free experience. So focus your energy. Tune in to: 